\title{
The role of mirror neurons in cognitive and social functioning*
}

\author{
Marta Fabiańska', A, Mateusz Bosiacki², B, Donata Simińska ${ }^{3, c 凶}$ \\ ${ }^{1}$ University of Szczecin, Institute of Philosophy and Cognitive Science, Krakowska 71-79, 71-017 Szczecin, Poland \\ 2 Pomeranian Medical University in Szczecin, Department of Functional Diagnostics and Physical Medicine, Żołnierska 54, 71-210 Szczecin, Poland \\ ${ }^{3}$ Pomeranian Medical University in Szczecin, Chair of Biochemistry and Medical Chemistry, Department of Biochemistry, Powstańców Wlkp. 72, 70-111 Szczecin, Poland \\ A ORCID: 0000-0002-2436-6002; $\quad$ B ORCID: 0000-0002-2279-4329; C ORCID: 0000-0001-8517-0364 \\ $\triangle$ d.siminska391@gmail.com
}

\begin{abstract}
Mirror neurons were accidentally discovered during research on the activity of nerve cells which was conducted by a team of Italian scientists in Parma. They observed that certain brain cells were activated when an animal performed a given activity but also when it observed a similar activity performed by someone else. The following discovery of mirror neurons in the human brain initiated a wave of experimental research which confirmed that mirror nerve cells are responsible for understanding the mental state of other humans. This process is much more complicated and important from an evolutionary point of
\end{abstract}

\section{INTRODUCTION}

The accidental discovery of mirror neurons by Italian researchers at the turn of the 1990s not only showed the location of a previously unknown type of nerve cell but also directed the attention of the scientific world to the cognitive mechanisms of empathy. Understanding these mechanisms as the basis for all human interactions has proven to be as important for the understanding of the nature of consciousness as the discovery of DNA was for biology. Mirror neurons may help us understand how a subjective world is created in our mind and how we come to understand each other as unique individuals by constantly exchanging experiences with others.

This work describes the properties of mirror neurons, with particular emphasis on their participation in fundamental cognitive processes related to human social activity. It has been prepared thanks to an impressive body of literature dedicated to various aspects of the mirror neuron system. The first part of the paper presents the daily manifestations of mirror neuron activity, i.e. the mirroring of other people's emotional and epistemic states of mind. The subsequent chapters explain this phenomenon in detail, based on a theoretical framework and empirical research. We discuss Baron-Cohen's classic "theory of mind" describing the 4 stages in the process of mirroring, how these were confirmed by experimental research and further developed based on research into the human brain. The final neurological part describes an extensive system of mirror neurons, taking into account the most important anatomical structures of the brain involved in various aspects of mirroring. view than it might initially seem. The activity of mirror neurons is noticeable in everyday life, during all interactions with other living beings. This is exhibited through mirroring - the reflection of emotional and epistemic mental states of others based on their behavior. We present the activities of mirror neurons and the theoretical framework of research. Finally, we discuss the results of neurological studies which have made it possible to locate and define in detail the role of the mirror neuron system in the human brain.

Keywords: mirror neurons; mind theory; autism; empathy.

\section{MULTIMODAL RESONANCE OF MIRROR NEURONS}

\section{Everyday resonance}

Everyday life is filled with countless events where we must evaluate the observed behavior of other people in order to assess their mental state, intentions, or goals of action and how we should respond to these. This happens continuously, automatically, directly, often completely unconsciously, and is something without which we could not function in society $[1,2$, 3]. This experience of 'emotional contagion', i.e. automatic sharing of other people's emotions, is done through a permanent but unconscious mirroring of other people's mental states in our mirror neuron system. It owes its name to the unusual activity of adjusting our conduct to fit the behavior of the observed person, resonating or tuning to the emotional and bodily state of the other person $[1,2,4]$. To better illustrate the concept of resonance, one could use an analogy of the resonance box of a guitar, where the vibration of one string makes the others vibrate. When someone assumes a certain facial expression indicating his or her satisfaction, their interlocutor will immediately pick it up, match it to the emotions of satisfaction, and then directly feel and understand the emotions of their companion in a given context $[2,3]$. The instrument's resonance box, on the other hand, can be compared to society - our social space where information is spread through sounds or non-verbal messages [5]. Since people do not differ from each other in terms of brain anatomy or in cognitive mechanisms, we have developed a common interpersonal area of meaning. This means that non-verbal signs characteristic of emotions are

\footnotetext{
* Based on the Bachelor thesis by Mrs. Marta Fabiańska: "Rola neuronów lustrzanych w poznawczym i społecznym funkcjonowaniu jednostki [The role of mirror neurons in cognitive and social functioning]" defended at the Institute of Philosophy and Cognitive Science of the University of Szczecin under the supervision of PhD Małgorzata Wrzosek. The original comprises 48 pages, 1 table, 3 figures, and 92 items of literature.
} 
universal for all members of society, and this is what enables communication based only on a look or facial expression [3, 6]. Apart from acts of emotional contagion, the phenomenon of resonance can be found in other situations involving mirroring, for example, when we spontaneously imitate observed behaviors. These can include situations such as when we follow the gaze of our interlocutor or cross our legs after the other person has done so [3]. These imitative behaviors may seem trivial and insignificant, but this is exactly how all small children between 1-3 years of age learn - by mimicking adult behavior. As we gain experience by imitating observed behaviors, we learn new things and develop as individuals as well as a species [7].

The resonance mechanism includes an intuitive, peculiar feeling about what is going to happen during and after an interaction. As a person's behavior can reveal numerous intentions - through eyebrow movements, the direction of gaze, tension, and restless hand movements, mirror neurons allow us to experience similar feelings which gives us the ability to understand the other person's intentions and identify a potential threat. Nevertheless, mirroring only works efficiently and is only credible in interpreting emotions; the greatest effectiveness in evaluating any given situation can be achieved by adding reason to the equation $[1,2,3,4]$.

An interesting aspect of the phenomenon of resonance is that it occurs even when observing behavior presented by actors on a screen. This indicates that the mind is able to recognize that the recording we are watching is a scene that could be observed in reality [8]. This means that each scene in a film or advertisement activates a system of mirror neurons, and the observed behaviors may be reproduced in a favorable situation [3]. This is a significant observation for the modern information society where the media tries to influence consumers to imitate the behavior on screen. It seems that by watching an advertisement in which someone purchases a given product, we increase the probability of buying it ourselves [9]. This works even more efficiently in the case of subliminal stimulation, i.e. when significant stimuli are presented in a time too short for them to be consciously perceived ( $40 \mathrm{~ms}$ ), and yet their processing takes place on an unconscious level and has an impact on consumer decision-making. After the influence of subliminal stimulation on people has been proven, its use was prohibited in advertisements [2,3].

Motor resonance is as important as emotional resonance. Observed primarily in the aforementioned spontaneous imitation of other people's behavior, it is also apparent in situations where there is difficulty in achieving consonance with another person. Mirror neuron systems differ in terms of their development which in practice means that some of us simply do not have the ability to show compassion or have some degree of difficulty with it [10]. This sense of alienation in certain groups of people at work or school results in their anxiety and manifests its self in many ways. Gaze is not reciprocated, attempts at conversation are ignored, and a number of subtle and sometimes incomprehensible signals suggest the undesirability of interaction. Such acts of social annihilation are used in bullying, often resulting in unpleasant consequences for the object of psychological harassment. Over time, stress deepens and may even affect one's immune system. In extreme cases, alienation can even cause depression and suicide attempts, which clearly demonstrates the importance of openness and mutual understanding between social contacts [3]. Resonance is often spoken of in the context of empathy, which seems to be the "most human" of all social phenomena and aptly reflects the essence of mutual understanding of one another's inner states $[11,12]$. Empathy is a very sophisticated form of behavioral transmission when compared to systems other animals employ and is made possible by an elaborate system of mirror neurons in the human brain. This unique feature of the human species may have enabled the rapid evolution of our brains, making Homo sapiens the most developed species on the planet in a relatively short time [13]. Thus, we can speak of empathy as a sophisticated form of imitation, thanks to which people are able to imitate not only the mechanical movements of limbs but also the subtle movements of the facial muscles, which allows us to experience the direct feeling of the other person's emotions [14]. If it were not for our ability to feel the emotions of other people, we would not be able to understand their problems and hidden needs and desires. Consequently, we would not be able to be altruistic and create things together. It should be noted that, compared to other animals, Homo sapiens show an exceptionally strong tendency to be altruistic, just as if it were a kind of default program of action. Without empathy, we would remain deaf to negative emotions and internal conflicts in the minds of other people in need of help, and as a result, each of us would be stuck in a primitive survivaloriented perspective, only satisfying our own needs. It is our ability to transcend this state of mind that distinguishes us from other living beings [15].

Mutual understanding and free communication enable a type of cooperation that is essential for a civilized and organized society consisting of various institutions that cannot exist without one another. It is only through the mutual exchange of experiences, their common analysis, and imitation of certain behaviors that we are able to understand the problems of individuals and of society, thus learning about the world and transforming it together [15]. This is only possible because people have created a symbolic form of recording knowledge in order to preserve and pass on the achievements of older generations to younger generations. In this way, younger generations can learn what older generations have created and improve on this. The process is repeated for each successive generation, which results in the so-called 'cultural ratchet effect'; as Homo sapiens cannot go back to previous stages of development, the achievements of previous generations are continuously improved upon. The cultural ratchet effect enables cumulative cultural evolution which is also influenced by a specific aspect of imitation, helped by the fact that only humans are able to imitate the ways and goals of a shared action [2]. Rizzolatti argues that due to the existence of 2 aspects of imitation, 2 types of mirror neuron resonance can be distinguished, high-level resonance allows us to understand the purpose of an action and low-level 
resonance allows us to imitate motion sequences [16]. Iacoboni adds that these 2 types of mirror neuron resonance are visible at the cerebral level - mirror neurons of the frontal cortex are responsible for understanding the purpose of action, and those in the parietal cortex for direct imitation [17]. This means that the human species is intelligent enough to understand that the same modes of action can be used to achieve different goals, and different goals can be achieved in different ways. Such a perspective has stimulated human creativity and caused the so-called combinatorial explosion, which resulted in various cultural inventions and a rapid transformation into a structured society $[1,16]$. The significance of the discovery of mirror neurons lies in the fact that explaining the phenomenon of resonance gives hope for the final unraveling of the mystery of the cultural evolution of Homo sapiens [13].

\section{Discovery of mirror neurons}

The discovery of mirror neurons, which constitute the neurobiological explanation of the resonance phenomenon, was made by a group of scientists from the Institute of Physiology at the University of Parma, led by Giacomo Rizzolatti. Their research concerned sensorimotor integration, i.e. how the brain plans what action to take based on sensory data (stimuli) coming from inside and outside the body [18]. The objects of interest for scientists in this context were the areas of motor neurons directing the muscles, and therefore responsible for action taken $[1,2,3]$. The first studies of this type were carried out on macaques and consisted of implanting very sensitive electrodes into individual neurons, directly in and around the vicinity of the $\mathrm{F}_{5}$ area of the motor cortex in the animal's brain. Their activity was then tracked while they performed various activities under laboratory conditions. The study showed that individual neurons in these areas of the brain were activated during the performance of purposeful movements. This meant that there were specialized nerve cells in the brain which, for example, would allow a hand movement to grasp fruit lying on a flat surface $[2,3,4]$. However, the motor neurons, on which Rizzolatti's team initially focused, are not the main link in the system underpinning the phenomenon of resonance. Instead, this is the role of mirror neurons, adjacent to the motor neurons in the F5 area, whose accidental discovery sparked a lively discussion about their role in the cognitive and social functioning of an individual [1]. During the study, some abnormal neuron activity was observed in the $\mathrm{F}_{5}$ area of the abdominal pre-motor cortex (the equivalent of Brodmann areas A44 and A45 in the lower pre-motor cortex, partially coinciding with the Broca area in the human brain $[1,3,19]$ ) in the macaque brain which occurred when the animal merely observed the researcher reach for the apple lying on the table. This neuron was the same neuron that was previously activated when the macaque performed a similar activity. This meant that a previously unknown type of nerve cell, responsible for the phenomenon of resonance, had just been discovered.

Further experiments showed that mirror neurons are activated not only when imitating or observing a given activity, but even when a macaque did not see an action but heard a sound characteristic of the activity. In the case of humans, it is enough to overhear a conversation about a specific action for the relevant neurons to become active and inform the subject about what is happening to the other person [2]. Mirror neurons therefore reliably perform their function regardless of the modality of stimuli needed to construct an appropriate representation. This phenomenon, initiated by the activity of mirror neurons, is called multimodal resonance [1]. This mechanism works by means of motor programs encoded in nerve cells which provide information on the sequence of activities characteristic of particular actions and multimodal representations which are systematically reflected in the mind [20]. Thus, each time a person senses specific emotions in their interlocutor, hears an unpleasant description of painful experiences, or directly observes how someone gets wounded, he immediately receives an internal representation of the proprioceptive experience that their companion is facing [2, 4]. We are able to feel and understand the other person's situation and react accordingly since we have an almost identical experience to that of the other person, with the slight difference that the representation we have is only an internal simulation of what is actually happening [3]. This mechanism provides a neurobiological basis for empathy and all other social phenomena that act on the same principle [1].

Mirror neurons are responsible for human movement and can be considered the basis of our cognitive functioning in general [21]. The aforementioned motor programs encoded in mirror neurons consist of individual sequences of action and the characteristics of these are recorded as the subject interacts with the outside world. By experiencing reality through observation and imitation, we record the initial sequence and then by repeating the activity on our own, we gain more and more certainty as to how the activity ends. Therefore, we do not have to observe the whole activity from the beginning to the end - it is enough for us to register its initial sequence so that we can understand the purpose of the activity and respond to it accordingly [1]. Without a system of mirror neurons, it would be impossible to enter a crowded tram, for example, because without the ability to directly understand the purpose of other people's actions, we simply could not protect ourselves from the rushing crowd taking the last available seats. It would also be impossible to carry out soccer competitions or other team games because, without the ability to predict the movements of teammates, an athlete would not be able to predict the trajectory of the ball's flight and go in the right direction [22].

This automatic and intuitive knowledge about the development of events arises only on the basis of one's own experience, and is therefore burdened with the possibility of error [4]. People are characterized by unpredictability in action and the initial sequence of the observed action, although it may be a very familiar occurrence, may result in a completely different outcome due to the ambiguity of gestures and other non-verbal signs [6]. Thus, when assessing an external situation, it is also worthwhile to support our assumptions with analytical thinking, thanks to which we can protect ourselves from the trap of our own automatisms which often force us to involuntarily 
perform reactions which do not guarantee success in every situation [3]. In conclusion, the discovery of mirror neurons has led to a new understanding of our own decision-making processes and the actions and mental states of other people. This is now the starting point for further reflections on the cognitive-social functioning of the individual.

A good theoretical basis for an in-depth study of the subject is Baron-Cohen's "theory of mind", which describes in detail the successive stages of mirroring - from the recognition of an object as an external actor, through shared attention, to the understanding of the mental state of the external actor [8] This theory was confirmed by the discovery of an extensive and complex system of mirror neurons existing in the human brain. The scientists in Parma did not stop at studying the mirror neurons discovered in the F5 area of the macaque's pre-motor cortex - in further experiments, the same class of neurons was also found in many other structures in the brain. These areas were found to work together in a neuronal circuit responsible for the most fundamental human cognitive activities, allowing researchers from around the world to look at these issues from a completely new perspective $[1,2,3,4,23]$.

\section{SIMON BARON-COHEN'S THEORY OF THE MIND}

Baron-Cohen's Mindblindness. An Essay on Autism and Theory of Mind offers a useful model of the mind which, as a system of hypothetical-theoretical assumptions, has been used to explain the human ability to immediately detect the state of mind of other people based on their behavior [24]. According to the author, this process is carried out through 4 mechanisms: "the intentionality detector" (ID), "the eye-direction detector" (EDD), "the shared-attention mechanism" (SAM), and "the theory-of-mind mechanism" (ToMM). These subsystems play different roles, working closely together to produce the so-called "theory of mind" - a subjectively constructed concept of the other person's current mental state. These mechanisms will be discussed in detail in the following sections of this chapter.

\section{Intentionality detector}

The ID is the 1st subsystem of the theory-of-mind. When activated, this mechanism mobilizes the other subsystems. It is therefore the initial stage of mirroring, taking place when at least 2 people interact. Therefore, the task of ID is to identify the so-called external agents and to interpret their movements as deliberate and motivated by a certain desire. The operation of this subsystem makes it possible to get a general sense of the observed scene, and it is said to be the most basic cognitive mechanism a child needs to start understanding other minds. Children between the ages of 18-24 months are in fact sensitive to spontaneous changes in an adult's intentions - it has been shown that they react differently to giving and pretending and that they already make attempts to do the same [25]. This indicates the child's understanding of the relationship between reality and the state of mind of the observed person [8]. The only condition that must be met in order for an object to be identified as an agent is self-excited movement [26] since this is the information that determines that we are dealing with another living being with a volitional state of mind. As such, there is an indifference to shape. Regardless of their size and how abstract they look, if they move by themselves, they are interpreted as agents. There are, however, situations in which the mind interprets inanimate objects as agents, such as a pool ball, a car, or a cloud, because at 1st they seem to move by themselves. However, after reflection we come to the conclusion that these objects move under the influence of some external force so they are not agents. The ID is triggered by a wide range of movements for evolutionary reasons - it is better to make a mistake by considering an inanimate object to be an agent and automatically go into combat mode, rather than ignore an agent that could pose a threat $[8,26]$. In this context, a useful feature of ID is also its ability to identify agents on the basis of sensory data coming from all basic modalities (sight, hearing, touch). In our daily life, we largely rely on vision when dealing with agents in the outside world which leads to underappreciation of our other senses. If, for example, we find ourselves in a completely dark room and suddenly hear a sound which is characteristic of a movement, or feel a hand on our shoulder, we realize that we are not alone and that this thing or person is conscious and can hurt us if that is his or her goal. In such a situation, the information provided by senses other than sight properly fulfill their role as they are able to alert the subject to the presence of another agent [8].

The existence of ID is supported by the 1944 Heider and Simmel study on a group of adult volunteers who were shown a silent film with geometric figures moving around the screen and then asked to describe what they had just watched. The results of the interview showed that in more than $90 \%$ of cases, there is a tendency to anthropomorphize the geometric figures - the participants did not give descriptions of the trajectory of movement of the shapes, but used the pattern to create a kind of narrative with characters and plot. The researchers explain the results of the study by the fact that the participants interpreted the movement of the figures as self-excited, thus treating them as agents moving forwards or backwards in order to achieve a goal or to move away from it. During the interview, numerous phrases were used that indicated the attribution of a volitional state of mind: "it wants", "it needs" etc. [27]. A few years later, similar experiments were also conducted with children and infants which, to the satisfaction of the researchers, gave identical results and allowed for the unequivocal confirmation of the existence of ID [8].

\section{Eye-direction detector}

Once the ID has played its role in locating the agent and classifying it as a living and conscious organism moving under the influence of a desire to achieve a goal, the cognitive system must then determine whether the goal is related to the cognitive subject. This information is provided by the EDD. As the name suggests, this subsystem only works through the sense of sight. The EDD is a specialized part of the human visual system and is stimulated by the eyes and any other related 
stimuli isolated from the observed faces. The purpose of this system is therefore to interpret the stimuli in terms of what the external agent sees. The EDD does this in 3 stages: eye detection, eye-direction detection, and the interpretation of seeing as perceiving [8].

In the 1st phase of operation, the EDD must interpret the perceived stimuli as the eyes of another organism. To do so, it fixates on them for some time and determines what they are doing. For a human being this is something completely natural because we have a preference to look into a person's eyes longer than the rest of their face, as can be seen in 2-monthold children [28]. Stern suggests that this is because, during breastfeeding, mother and child stay in a position where they can see each other's eyes. By repeating this activity every day at an early stage of development, the mother's eyes become natural stimuli for the child [29].

Once the eyes of another organism have been identified, the detector must determine whether they are directed at us or at something else. Just as with the over-compensation of risk assessment in the ID, realizing that we are in the agents field of vision increases vigilance and enables a quick transition to defense. Eye-direction detector does this by creating a representation of the relationship between our eyes and the agent's eyes, or whatever it is that the agent is looking at. When visual contact is established, the body is controlled by perceptible physiological arousal as evidenced by, for example, an increased galvanic skin response [30]. Considering that both children and adults usually react with a smile to a reciprocated gaze, it can be assumed that the emotions evoked in this way are positive. However, the level of physiological arousal induced by visual contact differs among children, which means that, depending on the intensity of the stimulation, the child will aim to achieve the optimal level of arousal by breaking or prolonging visual contact [29].

In the last stage, EDD interprets the agent's eye direction at a given object and assumes that the agent sees it. The ability to draw such a conclusion is probably already achieved as an infant through the experience of opening and closing their eyes - the child understands that when the eyes are open a visual experience occurs but is gone once they are closed. As the years go by, the child becomes able to generalize, so that he or she can conclude that this regularity also occurs with other agents [8].

The ID and EDD perform extremely important functions in the cognitive functioning of an individual, but their operation does not yet have much in common with the actual phenomenon of resonance. These systems operate on dyadic representations which means that their operation is noticeable within the cognitive relations between 2 objects (the cognitive subject and the agent, and the agent and object), but is not enough to discuss obtaining a shared picture of reality. This is provided by an additional subsystem, one that elevates the entire process to a higher level, allowing for contact between several minds [8].

\section{Shared-attention mechanism}

The SAM differs from the aforementioned 2 subsystems in the theory-of-mind because its main function is to create triadic representations or the relationship between 3 objects. This means that the mechanism is activated when there are at least 2 agents (the cognitive subject and the external agent) and an object (an object or another agent) on which both focus. Thus, creating a triadic representation is tantamount to realizing that both the cognitive subject and the agent see the same object on which they can communicate freely, confident that they both know what they are talking about [8].

The pursuit of shared attention is already visible in children between 9-14 months of age. For example, children often employ a so-called protodeclarative gesture of 'pointing out' through which the child induces the other person to concentrate their attention on the object the child is interested in [31]. In order to build a triadic representation, SAM requires information about the other person's perceptional state, which it gains through the ID and EDD i.e. previously created dyadic representations. This means that each triadic representation contains 2 nested dyadic representations - i.e. the representations of the perceptional state of 'me' and 'the agent'. This relationship indicates the cooperation of the 3 subsystems [8]. In order to obtain the necessary information, the SAM retrieves data from all possible senses - although it seems that the most important are those related to the direction of the other person' gaze, i.e. the dyadic representations created by EDD through the sense of sight. The mechanism compares our direction of vision with the agent's direction of vision to determine whether the attention of both people is focused on the same object. Using the information offered by EDD is by far the easiest and quickest way for SAM to determine the fact of shared attention, and therefore the relationship between the 2 systems is thought to have a privileged status [3]. The limitation of this mechanism is that sight only makes it possible to determine what objects both agents are concentrating on within our field of vision. With reference to other senses, identifying the shared attention is more difficult since it is impossible to determine whether 2 different people have the same sensory quality of taste or smell [8]. The process of creating triadic representations also involves ID. Through SAM, the output from ID becomes available to EDD, so that the object on which 2 people are focused on can be interpreted as their common goal [8].

In 1992, a group of researchers conducted a study on children aged between 9-18 months in order to confirm the hypothesis of their interpretation of eye-direction in terms of target detection. During the experiment, the researchers presented both clear and ambiguous actions to the children and then observed their reactions. The results showed that in the case of ambiguous actions, the children's reflex reaction was to direct their gaze directly at the experimenter's eyes, which can be interpreted as a search for information about the purpose of the action [32]. The experiment shows that the intentional reference of at least 2 people to the same object is only possible if the 3 aforementioned systems work closely together - a lack of data from any of them makes the process impossible [8].

The interaction of ID, EDD, and SAM gives some knowledge on what is happening to the other person by enabling us to communicate with them about the reality we see together, 
although the triadic representations generated by SAM are still not enough to understand and read other people's minds. For the resonance phenomenon to occur, a person still needs information about the more complex states of mind of the other person and the possibility to coordinate all the data obtained. This is the function of the last element of the presented model, the ToMM.

\section{The theory-of-mind mechanism}

The ToMM is superior to the other subsystems because its main task is to coordinate all the information that ID, EDD and SAM have obtained. However, before it can integrate the data, it must supplement this with the final pieces of information which it acquires on its own [8]. The aspects dealt with by ToMM are the so-called epistemic states of mind, i.e. states related to complex cognitive activities, such as thinking, judging, pretending, or imagining. The ToMM recognizes such states by representing the suggestive attitudes of agents as mental representations (agent - attitude - statement). For example, when talking to a friend about the weather, the mechanism represents the friend's propositional attitude as: (Matthew - thinks - it's "raining"), so that it can determine the friend's epistemic state of mind, which in this case is "thinking". The mental representations, therefore, are the medium through which we are able to understand what is happening to the other person - they allow us to ascertain his or her subjective state of mind in a given situation and to distinguish it from our own [33]. At this point, attention should be paid to the key property of epistemic states of mind, namely their so-called referential opacity. Referential opacity refers to the fact that the claim on which the agent's propositional attitude is directed can be false, although the whole mental representation is true. This phenomenon can be explained with the aforementioned example. The representation (Matthew - thinks - "it's raining") is true because Matthew actually said aloud "I's raining" and there is no indication that he is lying or joking and therefore, he really believes that it is raining. If, however, in reality, it is snowing and not raining then Matthew's claim is false, although the whole representation is true.

The process of reading the epistemic states of mind seems quite complex, but in actual fact, its effects are already noticeable in properly developing children between the ages of 18-24 months as this is the age where children begin to prefer games based on the most basic epistemic state of mind, i.e. pretending [34]. In the next stage of development, children also begin to understand the principle that knowledge is a product of perception [35] and that people sometimes have beliefs in relation to reality that can either be true or false, which indicates that they perceive the opacity of epistemic states [36]. In 4- and 5 -year-old children, the action of ToMM is already very sophisticated. This is shown by their understanding of fairy tales with storylines based on misunderstandings caused by deceit, and by their own use of deception in everyday situations [37]

Once ToMM has acquired the relevant information, it can proceed to its 2 nd task, i.e. to merge all the data acquired by the 4 subsystems into 1 coherent theory of the other person's mind. This is done by retrieving information from the ID and EDD via SAM, which indicates that there is an equally privileged relationship between ToMM and SAM as there is between SAM and EDD. The triadic representations generated by SAM can also use the other person's propositional attitudes, thus providing the appropriate input for ToMM which quickly and efficiently transforms the SAM's triadic representations into its own M-Representations, completing the entire process of reading the other person's mind [8].

In summary, this chapter presents the 4 mechanisms responsible for carrying out the process of mirroring, which correspond to the 4 stages of forming assumptions of a person's intentions. This process, although it includes several stages and requires different types of knowledge, is almost instantaneous and is present during every moment of interaction with other people or animals. However, not every one of these mechanisms is part of our evolutionary devices. Table 1 summarizes which stage of human development is affected by the appearance of cognitive abilities corresponding to each of the theory-of-mind subsystems.

TABLE 1. Mean values \pm standard deviation (SD) of the biochemical parameters of the efficacy of kidney storage

\begin{tabular}{|c|c|c|}
\hline $\begin{array}{l}\text { Name of the } \\
\text { mechanism }\end{array}$ & $\begin{array}{l}\text { Cognitive abilities, specific } \\
\text { to a given mechanism }\end{array}$ & $\begin{array}{l}\text { Period } \\
\text { of development }\end{array}$ \\
\hline $\begin{array}{l}\text { Intentionality } \\
\text { detector (ID) }\end{array}$ & $\begin{array}{l}\text { 1. detection of the purpose } \\
\text { of action - interpretation } \\
\text { of self-excited movement } \\
\text { as indicative of the } \\
\text { presence of another agent } \\
\text { manifesting a volitional } \\
\text { states of mind, } \\
\text { 2. building dyadic } \\
\text { representations }\end{array}$ & $\begin{array}{l}\text { innate } \\
\text { mechanism: } \\
\text { development } \\
\text { from birth } \\
\text { to about } 9 \\
\text { months of age }\end{array}$ \\
\hline $\begin{array}{l}\text { Eye-direction } \\
\text { detector } \\
\text { (EDD) }\end{array}$ & $\begin{array}{l}\text { 1. recording of stimuli } \\
\text { related to the eyes, } \\
\text { 2. monitoring eye-direction, } \\
\text { 3. interpreting the eye- } \\
\text { - direction in terms of } \\
\text { target detection, } \\
\text { 4. building dyadic } \\
\text { representations }\end{array}$ & $\begin{array}{l}\text { innate } \\
\text { mechanism: } \\
\text { development } \\
\text { from birth } \\
\text { to about } 9 \\
\text { months of age }\end{array}$ \\
\hline $\begin{array}{l}\text { Shared- } \\
\text {-attention } \\
\text { mechanism } \\
\text { (SAM) }\end{array}$ & $\begin{array}{l}\text { 1. giving attention to an } \\
\text { object/entity that is the } \\
\text { other agent's reference } \\
\text { target, based on the } \\
\text { direction of the agent's } \\
\text { gaze, } \\
\text { 2. building triadic } \\
\text { representations }\end{array}$ & 9-18 months \\
\hline $\begin{array}{l}\text { The theory- } \\
\text {-of-mind } \\
\text { mechanisms } \\
\text { (ToMM) }\end{array}$ & $\begin{array}{l}\text { 1. recognizing one's own and } \\
\text { others' epistemic states } \\
\text { of mind - distinguishing } \\
\text { between physical and } \\
\text { non-physical entities, } \\
\text { 2. building mental } \\
\text { representations } \\
\text { on the basis of reading } \\
\text { propositional attitudes }\end{array}$ & 18-48 months \\
\hline
\end{tabular}


The phenomenon of resonance is not merely a theoretical proposition of scientists - it is a real complex cognitive process occurring through the mirror neuron system in the human brain. This system involves many anatomical structures whose functions correspond to those of the individual mind theory subsystems discussed here, confirming Baron-Cohen's assumptions about the mechanisms that work during human interactions.

\section{MIRROR NEURON SYSTEM IN THE HUMAN BRAIN}

\section{Development of the mirror neuron system}

The ability to imitate has shaped modern humans into a highly developed civilization full of various cultural creations and is somewhat inscribed in its genetic code [38]. The development of the system of mirror neurons is carried out according to the genetic program, i.e. through phylogenetic mechanisms related to the sensory-motor activity of Homo sapiens. The readiness of an individual to automatically and effortlessly imitate simple activities is therefore a consequence of ancestors who were exposed to constantly repeated activities undertaken under specific conditions. The kind of activities they are depends on the general sensory-motor specificity of the whole species, something which is shaped over centuries [21]. The system of mirror neurons, prepared in a genetically modified way, starts to function as early as the fetal period when the baby's organism is still developing in the womb [38]. The activity of mirror neurons is very important here because they are the basis for the primary communication between mother and child, consisting of mutually tuning of their mirror neuron systems. This connection forms the basis for the further development of the ability to imitate and communicate with other people and general development in both cognitive and social functioning, based on a fundamental distinction between "I" and "others". The primitive imitation of one's mother in this stage makes the imitation of other adults performing basic activities easier and more effortless for children postpartum and during infancy [39]. However, this becomes increasingly difficult over time as personal experiences makes us aware of the ambiguity of the activities observed, i.e., their various possible outcomes, whose prediction depends on the correct inference and interpretation of the situational context [21].

\section{Multidimensionality of the emphatic reaction}

The phenomenon of resonance is often equated with human empathy, which is not entirely incorrect because empathy is central to social understanding. It would, however, be wrong to say that empathic reactions are only caused by the mirroring of emotions. Resonance is a multidimensional reaction that takes into account not only the affective but also the cognitive and motor components of experience [39]. Information about the cognitive subject and external agents is represented at many levels and by the various modalities available to the nervous system $[17,21,23]$. At the cerebral level, the multidimensionality of the empathic reaction takes place through the activities of numerous brain structures, integrated by means of a network of mirror neurons, involved in processes related primarily to mimicry, language, motor activities, empathy, and the creation of theories [39]. These capabilities constitute the core of the mirroring phenomenon, and thus, analogically, the structures that make up their neurological background constitute the core of the mirror neuron system. These structures mainly include the sensory-motor cortex, the premotor cortex, the inferior frontal gyrus, the inferior parietal lobule, the superior temporal sulcus, the middle temporal gyrus, and the insular cortex [40, 41]. Among them, particular attention should be paid to the pre-motor cortex, specifically Brodmann areas A44 and A45, partially overlapping with the Broca area - as this part of the cortex has the largest concentration of mirror neurons [3]. Contributions from the areas of the brain related to perception, memory, analytical thinking, and many other aspects of resonance are also significant [40]. Since the system of mirror neurons takes the form of a network connecting individual brain structures, its 1st function is to synthesize information obtained through these. At the same time, this function constitutes the 1st stage of mirroring aimed at defining the perspective of the subject's "Self". The perspective of the "Self" is treated here as the state of mind of the cognitive subject at the present time, taking into account his or her well-being, previous experiences, attitudes, and views relevant to the situation $[39,40]$. It is only after this synthesis that mirror neurons begin their main task, which is to tune their activity to the activity of the mirror neurons and brain structures of the external subject. Mirroring can therefore be known as the communication between the brains of 2 (or more) subjects, aimed at creating a shared experience by producing a simulation of it in the subjects brain. With a simulation that is multimodal and on multiple levels, we can feel what the other person feels at a given moment and relate to it accordingly [39, 42]. However, it should be remembered that interpreting the observed actions by the filter of one's own "Self" creates the risk of making mistakes in the attribution of the other person's views, goals, or intentions. Such errors are called egocentric errors because they result from personal experience or deficits in the functions of the individual brain structures of the cognitive subject. For example, if a person has a deficiency in the functioning of the insular cortex and therefore has problems identifying emotions of anger in himself, there will also be anomalies in identifying emotions of anger in others. These errors also include the everyday misunderstandings that arise from prejudices or negative experiences with people or situations which are similar to what we are experiencing in the moment $[17,43]$. The mirroring process is a process that requires an incredible speed of reaction and precise synchronization of the activity of many areas of the brain, which makes it difficult to separate the processes responsible for its different aspects. However, within the main abilities that are relevant to resonance (mimicry, language, motor activity, empathy, theory-of-mind creation), special relationships can be found between language and motor activities, and empathy and theory-of-mind processes [39]. These dependencies will be described in the following subsections. 


\section{Integrating the function of the mirror neuron system with respect to language and motor activity}

The system of mirror neurons is called a trimodal system because, for the processes of understanding speech, the cognitive subject requires motor, auditory and visual stimuli, processed in an integrated way. This system takes the form of a neural network, combining the sensory-motor, temporal and parietal structures of the cerebral cortex in the left hemisphere [44]. Although all 3 aspects are equally important for the development of speech-related abilities, the participation of the motor system deserves special attention. In the brain, the eloquent cortex is involved in both linguistic processes and motor activity, mainly including the Broca area (in the inferior area of the frontal lobe), the primary motor cortex, the additional motor cortex, and the pre-motor cortex [45]. However, learning a language through the motor system and mirror neuron system is largely possible due to the specificity of the Broca area and the Wernicke area whose activity stimulates the motor system. The Broca area is responsible for generating speech and controlling the movements of the muscles of the face, cheeks, and lips that are active during speech. Located in the posterior dorsal area of the temporal lobe, the Wernicke area is responsible for carrying out processes related to understanding speech. Thus, the proper functioning of the Wernicke area and the Broca area determines the proper course of language development, which is confirmed by documented cases of difficulties in language development in people with congenital or acquired damage to the inferior frontal and temporal areas of the cerebral cortex $[39,46]$.

The connection between language and motor abilities is apparent even in the fetal period of human development, specifically in the 3rd trimester of pregnancy when the fetus' brain develops intensively, especially in terms of the sensory-motor cortex. The process of speech development is connected with the fetus' movements in the womb and with external stimulation in the form of mother-child conversation. Through a system of mirror neurons, eloquent areas of the mother's brain, active during speech, stimulate and develop analogous structures of the child's brain. The link between language and the motor system is that the movements imitated by the child are mainly those of the movements of the mother's facial muscles during articulation which constitutes a rudimentary form of communication at birth [21]. Thus, mirror neurons enable the learning of language because of their ability to map the representations of communication using the senses onto the personal representation of the motor activity. This allows the cognitive subject to get into a state of readiness to take a given action [39, 47]. This kind of motoric ability, obtained from the mother through a system of mirror neurons during the fetal period, allows the child to reach an understanding with other subjects via mirroring even before he or she starts communicating through words. Wordless communication is therefore a primary form of speech since internal speech, indicated by gestures, activates the same pre-motor cerebral cortex communication system as speech. This area, as already mentioned, has a dense network of mirror neurons responsible for action planning, which indicates the significant participation of mirror neurons in the process of understanding non-verbal messages. At the cerebral level, these messages take the form of single electrical signals transmitted between nerve cells - just like with spoken words [38]. The language and gestures of nonverbal communication with motor activities are linked to the human ability to use tools. The left parietal cortex, associated with the control for gestures and the manipulation of objects, is connected by an integrative network of mirror neurons within the areas of the cerebral cortex close to the tegmentum, which takes part in language-related processes [44].

The activity of the mirror neuron system, noticeable in the process of shaping linguistic abilities, seems to support Noam Chomsky's popular theory about the innate nature of human language [39]. Chomsky postulated the existence of so-called universal grammar, that is, a genetically determined initial state of linguistic ability conditioning the universal structure of natural languages. The development of this initial stage is thought to be established by biological processes, i.e. through the activity of appropriate brain structures responsible for linguistic abilities, primarily in the Broca area and the Wernicke area [46]. Advances in neuroscience have allowed us to look at this linguistic-biological theory from a new perspective, complement it with additional brain structures associated with linguistic abilities and indicate the significant role of mirror neurons in interpersonal communication, closely related to the activity of the motor system [39].

\section{The integrating function of mirror neurons in relation to empathy and the theory of mind}

For the phenomenon of resonance, it is important to imitate movements faithfully and to understand the intentions and purposes of the activity for other people. As already mentioned, these abilities refer to low- and high-level resonance, respectively. The observations of the activities of the human brain connected with empathizing and mentalizing indicate the importance of these 2 aspects of mirroring $[16,17,44]$. The main areas of the brain associated with empathy are considered to be the posterior frontal gyrus and the adjacent part of the pre-motor cortex, i.e. exactly the same area in which high-level resonance activity is attributed. Low-level resonance activity is mainly associated with the parietal cortex, responsible for the mirroring of bodily sensations $[17,39]$. Observing the various aspects of multi-dimensional empathic responses, researchers found that the processes related to empathy and those related to the creation of the theories of mind, although distinctive in and of themselves, are closely connected. Despite their common neurological background (the inferior frontal cortex, pre-motor cortex, superior temporal cortex, insular cortex, amygdala, and medial prefrontal cortex) they are not the same [23]. Therefore, 2 types of empathy may be distinguished, cognitive empathy and emotional empathy.

The 1st type is related to the ability to accept the perspective of another person, i.e. the ability to create a theory of mind. The basis of this ability is to perceive and experience one's own and other people's mental states, for which the medial 
prefrontal cortex is primarily responsible. If, in addition, brain structures such as the insular cortex, the anterior and dorsal anterior cingulate cortex, the premotor cortex, and the basal ganglia are activated, then emotional empathy appears. This empathy is connected with experiencing emotional states, i.e. our ability to recognize moods, or showing strong emotional reactions as a result of observing someone experiencing pain [17, $21,23,39]$. Already at this stage of mirroring we can see how extensive the empathic reaction is and how subtle the boundaries between individual abilities are, seamlessly working in tandem, both in the individual experience and at the neurological level. In order to illustrate the mirror activity of the brain, which takes place during interactions with other living beings, it is necessary to trace the path of the electrical signal transmitted between the nerve cells - from the reception of the external stimulus, through the sharing of the experience, to the mapping of activities or the construction of a theory of the mind of the other person.

\section{Neurological background of Simon Baron-Cohen's theory of mind}

Baron-Cohen has distinguished 4 stages of mirroring with 4 respective "cognitive devices": the ID, the EDD, the SAM, and the ToMM. Baron-Cohen's proposition seems to be a highly theoretical explanation of the human capacity for mentalization. However, his theory can be supported by mirroring recorded during the performance of cognitive activities as these correspond to the tasks of individual modules of the theory of mind. In fact, thanks to its synthesizing and reflecting functions, the mirror neuron system is the structure responsible for distinguishing between the "Self" and "others", for sharing experiences and understanding the mental states of other subjects which makes it possible to consider it the neurobiological foundation of Baron-Cohen's theory. The following section will provide neurological evidence to support this thesis $[3,8]$.

The process of mirroring, as already known, only occurs between living beings - the mirror neuron system is not activated in interactions with inanimate objects that do not move with a self-excited motion and do not manifest a volitional state of mind $[3,8]$. Joachim Bauer suggests that the mirroring process begins with the recording of a moving visual stimulus through cones and rods, i.e. visual receptors located on the retina inside the eyeball. The receptors form synaptic connections with ganglion cells, for example, whose axons intertwine in the optic nerve from where signals coding the shape, color, and motor aspects of the stimulus, leave the eyeball. Having completed a visual pathway, where they go through the optic chiasm, thalamus, and lateral geniculate nucleus, they reach the occipital lobe of the visual cortex, where they are transformed into representations of what our eyes have observed [48]. The occipital lobe is connected to the temporal lobe by 2 nerve fibers on both sides of the brain. Through these fibers, the information from the visual cortex enters the superior temporal sulcus, i.e. the visual processing and interpretation system. There, on the basis of the motor aspect, a decision is made as to whether the observed object is a living agent - if so, the brain receives information that mirroring can begin [3]. A similar temporal lobe activity in monkeys, after they have observed an object moving in a self-excited motion, has prompted researchers to consider this area as the cerebral location of the ID - the 1st of the cognitive devices proposed by the Baron-Cohen [8]. An issue that needs to be clarified here is that contrary to the assumptions of the author of "theory of mind", the mirror neuron system also reacts to accidental movements and not just those that are intentional. However, Baron-Cohen's hypothesis is not completely wrong, since the variant he proposed does occur in animals other than humans [47]. Bauer suggests that the superior temporal sulcus is also responsible for the processes assigned to the EDD and the SAM. This area is also responsible for determining the direction of vision in other subjects, on the basis of which it determines the object of their interest and the potential object of shared attention [3]. Mirroring of facial expressions via the determination of another person's gaze also involves the inferior frontal cortex, prefrontal cortex, insular cortex, and amygdala [43]. At the level of the superior temporal sulcus, the cognitive agent is already aware that he or she is in contact with a living being who is moving in the direction suggested by the direction of his or her gaze. Humans usually direct their gaze in the same direction as the other person completely automatically, thoughtlessly and immediately, although at the cerebral level, there is still a long way to go before we can finally reflect the motoric movement or create a theory of the other person's mind. In the next stage, the brain must determine whether it is safe to continue mirroring. This is done at the level of the primary sensory cortex, whose cells record the sensations from skin and connective tissue and determine where the stimulation comes from. Then, the associated lower parietal cortex sensory cells form an internal representation of the sensory consequences of the movement [3].

The primary sensory cortex also has numerous connections with other brain structures responsible for emotional empathy, the most important of which are the insular cortex and cingulate cortex [47]. They are, respectively, the cerebral centers of emotion, and the area responsible for pain sensation and the production of pain representations as a result of observing someone who is physically harmed [3]. When the mirroring of a given activity proves safe for the cognitive subject, the activity of the system moves to the area of the pre-motor cortex, where at the same time the planning of one's own activity and reading of the observed goals and intentions takes place. Mirror neurons of the pre-motor cortex have inter-modal properties, which means that the reading of the purpose or intention of action can be based on data from different modalities rather than just sight [39, 44]. From there, the signal can be transmitted to the motor cortex, which results in a mapping of the previously observed movement, or it can be stopped at the level of pre-motor neurons. However, processes ending with the motor cortex concern low-level resonance, based on faithful imitation [3]. High-level resonance, associated with the reading of the agent's intentions, also involves the cortical-central structures of the brain, i.e. the area most closely related to the creation of 
the theory-of-mind. In addition to the temporoparietal junction and superior temporal sulcus described earlier, these include the middle frontal cortex with the adjacent anterior cingulate cortex and the temporal poles. They are responsible for higher cognitive functions related to understanding, thinking, and language, and are also able to use different modalities which means that they coordinate various types of perceptual information. Among them, the neurological background of the last of the theory-of-mind modules are primarily considered to be the frontal and prefrontal cortex, whose activity enables us to adapt to new situations and to understand other points of view. On the other hand, the structures of the middle temporal lobe are responsible for the ability to imagine the future and is linked to the adoption of the other person's perspective. Cortical-central structures, together with the sensory organs, are also responsible for the precise reading of the situational context of interaction [39]. It should be noted that for a close cooperation between the frontal lobe and the temporal lobe, it is necessary to combine them with structures responsible for emotions, simulation, motor activities, and language [47]. The process of mirroring also involves the participation of executive functions, which ultimately indicates that the creation of the theory of the other person's mind is the result of a multidimensional empathic reaction, rather than the activity of a particular module in the mind [39].

In summary, mirror neurons 1st synthesize the activity of brain structures, which allows them to define the perspective of the "Self". They then tune in to the pattern of activity of the observed agent, activating analogous brain structures to create a simulation of the other person's experience. Inter-modal information about the self and the other subject is then juxtaposed by the frontal areas of the brain into a coherent theory of the other person's mind. In all properly developing people, this system works on the same principle although its effectiveness depends on the overall sensitivity of the individual. This means that, depending on the degree of reactivity of the nervous system, we will find people who are more attuned or less attuned to stimulation. In practice, highly sensitive individuals show an increased awareness of the mirroring processes that take place in interactions with others, which makes them intuitive and they will usually consider themselves to be more empathic [39]. We can also find people whose differences are due to certain irregularities, primarily autism spectrum disorders (ASD), whose cognitive dysfunctions cause significant problems in developing theoris-of-mind [49].

\section{SUMMARY AND PERSPECTIVES FOR FURTHER RESEARCH}

The data collected and summarized in this paper on the cognitive-social manifestations of mirror neuron activity in humans, clearly indicate that the discovery of these neurons as a major event in science is not an exaggeration. By revealing the mechanisms of understanding actions and reflecting the mental states of others, these cells have clarified many problematic issues in scientific research. What initially appeared to be a cluster of several new, specific nerve cells, turned out to be an extensive neural network integrating the most important structures of the cerebral cortex. The analysis of the processes carried out by mirror neurons has shaken the scientific world up as it seems to undermine the thesis of mind modularity while pointing to the multidimensional nature of the empathic reaction. The processes associated with understanding the actions of others have proved to include many more factors than initially thought, and their interdependence seems to play a key role. However, despite promising prospects, researchers warn that there is still a long way to go. The broken mirror theory and the theory of mentalism have been only been developed relatively recently and still require a lot of research before we are able to develop effective cognitive therapy for people with ASD [50].

Many scientific publications suggest that mirror neurons, along with other significant findings in neuroscience, can contribute to improving the quality of didactics and the process of rehabilitation. It has been noted that teaching methods including cognitive mimicry and imitation mechanisms are much more effective than classical methods. Therefore, schools are increasingly using project-based teaching, with an emphasis on creative activities, cooperation, and efficient communication. Such changes aim to familiarize students with the realities of professional life by teaching them how to deal with stress which is often caused by public speaking or the inability to work in a group [51]. For individuals with behavioral problems undergoing rehabilitation, drawing their attention to empathy, and working with emotions as essential factors in the decision-making process has been effective. Positive psychology also draws attention to the existence of brain neuroplasticity - any negative patterns of behavior can be replaced by new ones that benefit both the individual and the society in which he or she lives. The brain never stops developing, and personal development is all the more effective if we learn about ourselves through interactions with others [52].

Although the discovery of mirror neurons has created intriguing perspectives for science and social life, there are some prominent critics. Hickok expressed his objection to the theory of mirror neurons in his book entitled The myth of mirror neurons [53]. For example, Hickok doubts the participation of mirror neurons in reading the situational context that is essential for a full understanding of messages. He argues that mirror neuron activity is not enough to provide a comprehensive picture of a situation. On other hand, Rostowski and Rostowska believes that it is the reflective function of mirror neurons that enables adaptation to various situations by inhibiting or stimulating adequate responses [39]. Hickok also doubts the fundamental issue of linking mirror neurons to empathy, which he claims requires understanding that needs "more" than just a simple mirroring of emotions [53]. However, we showed that empathy can be divided into emotional and cognitive categories, and that mirror neurons do not work alone but in the company of other brain structures that complement the process with the information necessary to fully understand the state of mind of other people. The discovery 
of mirror neurons is undoubtedly an absolute breakthrough in the field of cognitive science, showing the significance of empathy and reciprocity as the fundamental factors of social life. Perhaps when we realize how the brain creates a subjective mind based on every little bit of information, we will understand how important every single individual is for a society. This may also help finally unravel the mystery of consciousness and help us enter the era of artificial intelligence.

\section{REFERENCES}

1. Brożek B, Hohol M. Umysł matematyczny. Kraków: Copernicus Center Press; 2015. p. 295-303.

2. Sosnowska B. Czy neurony lustrzane stanowią współczuciowy podkład ludzkiej moralności. In: Kojder I, red. Neurokognitywistyka w patologii i zdrowiu 2009-2011. Szczecin: Wydawnictwo Pomorskiego Uniwersytetu Medycznego w Szczecinie; 2011. p. 21-32.

3. Bauer J. Empatia. Co potrafią lustrzane neurony? Warszawa: PWN; 2008.

4. Cattaneo L, Rizzolatti G. The mirror neuron system. Arch Neurol 2009;66(5):557-60.

5. Goban-Klas T, Sienkiewicz P. Społeczeństwo informacyjne. In: Społeczeń stwo informacyjne: Szanse, zagrożenia, wyzwania. Kraków: Wydawnictwo Fundacji Postępu Telekomunikacji; 1999. p. 42-95.

6. Osika G. Komunikacja niewerbalna. Zeszyty naukowe Politechniki Śląskiej: Organizacja i Zarządzanie 2008;43:147-67.

7. Tomasello M. Kulturowe źródła ludzkiego poznawania - oceny, opinie, ceny. Warszawa: Państwowy Instytut Wydawniczy; 2002.

8. Baron-Cohen S. Rozwój zdolności czytania innych umysłów: cztery etapy. In: Klawiter A, editor. Formy aktywności umysłu. Ujęcia kognitywistyczne: ewolucja i złożone struktury poznawcze. Warszawa: PWN; 2009. p. 145-71.

9. Sanecka E. Manipulacja w reklamie telewizyjnej skierowanej do dzieci i młodzieży. Kultura-Media-Teologia 2013;13(2):19-36.

10. Czerniawska M. Empatia a system wartości. Prz Psychol 2002;45(1):7-18.

11. Baron-Cohen S. Theory of mind and autism: A review. Int Rev Res Ment Retard 2000;23:169-84

12. Whiten A. Evolving a theory of mind: the nature of non-verbal mentalism in other primates. In: Baron-Cohen S, editor. Understanding other minds: perspectives from autism. Oxford: Oxford University Press; 1993.

13. Ramachandran VS. Neuronauka o podstawach człowieczeństwa. Warszawa: Wydawnictwa Uniwersytetu Warszawskiego; 2012.

14. Fritch Ch. Od mózgu do umysłu. Jak powstaje nasz wewnętrzny świat. Warszawa: Wydawnictwa Uniwersytetu Warszawskiego; 2011.

15. Tomasello M. Dlaczego współpracujemy. Kraków: CCPress; 2009

16. Rizzolatti G. The mirror neuron system and imitation. In: Hurley S, Chater N, editors. Perspectives on imitation: mechanisms of imitation and imitation in animals. Cambridge: The MIT Press; 2005. p. 55-76.

17. Iacobini M. Understanding others: imitation, language, empathy. In: Hurley $S$, Chater N, editors. Perspectives on imitation: from cognitive neuroscience to social science. Cambridge: MIT Press; 2005. p. 77-99.

18. Wasilewski TP. Integracja sensoryczna i jej znaczenie dla funkcjonowania i rozwoju mowy dziecka. Pediatr Med Rodz 2018;14(1):20-32.

19. Gazzola V, Keysers C. The observation and execution of actions share motor and somatosensory voxels in all tested subjects: single-subject analyses of unsmoothed fMRI data. Cereb Cortex 2009;19(6):1239-55.

20. Fogassi L, Ferrari PF, Gesierich B, Rozzi S, Chersi F, Rizzolatti G. Parietal lobe: From action organization to intention understanding. Science 2005;308(5722):662-7.

21. Oberman LM, Ramachandran VS. The simulating social mind: The role of the mirror neuron system and simulation in the social and communicative deficits of autism spectrum disorders. Psychol Bull 2007;133(2):310-27.

22. Hohol M, Urbańczyk P. Some Remarks on Embodied-Embedded Social Cognition. In: Emotional Brain Revisited. Kraków: Copernicus Center Press; 2014.
23. Decety J, Jackson PL. The functional architecture of human empathy. Vol. 3 , Behavioral and cognitive neuroscience reviews. Behav Cogn Neurosci Rev 2004;3(2):71-100.

24. Chlewiński Z. Umysł: Dynamiczna organizacja pojęć. Analiza psychologiczna. Warszawa: PWN; 1999.

25. Leslie AM. ToMM, ToBy, and Agency: Core architecture and domain specificity. In: Hirschfeld LA, Gelman SA, editors. Mapping the mind. Domain specificity in cognition and culture. Cambridge: University Press; 1994.

26. Mandler JM. How to build a baby: II. Conceptual primitives. Psychol Rev 1992;99(4):587-604.

27. Heider F, Simmel M. An experimental study of apparent behavior. Am J Psychol 1944;57(2):243-59.

28. Maurer D, Barrera M. Infants' perception of natural and distorted arrangements of a schematic face. Child Dev 1981;52(1):196-202.

29. Stern DN. The interpersonal world of the infant: a view from psychoanalysis and developmental psychology. New York: Basic Books; 1985.

30. Siegman AW, Feldstein S. Multichannel integration of nonverbal behavior. New York: Psychology Press; 2014.

31. Lempers JD, Flavell ER, Flavell JH. The development in very young children of tacit knowledge concerning visual perception. Genet Psychol Monogr 1977;95(1):3-53.

32. Phillips W, Baron-Cohen S, Rutter M. The role of eye contact in goal detection: evidence from normal infants and children with autism or mental handicap. Dev Psychopathol 1992;4(3):375-83.

33. Leslie AM, Thaiss L. Domain specificity in conceptual development: neuropsychological evidence from autism. Cognition 1992;43(3):225-51.

34. Leslie AM. Pretense and representation: the origins of "Theory of Mind". Psychol Rev 1987;94(4):412-26.

35. Pratt $C$, Bryant $P$. Young children understand that looking leads to knowing (so long as they are looking into a single barrel). Child Dev 1990;61(4):973-82.

36. Wellman HM. The child's theory of mind. London: The MIT Press; 1990.

37. Sodian B, Frith U. Deception and sabotage in autistic, retarded, and normal children. J Child Psychol Psychiatry 1992;33(3):591-605.

38. Watkins K. Developmental disorders of speech and language. Prog Brain Res 2011;189:225-38.

39. Rostowski J, Rostowska T. Rola systemu lustrzanych neuronów w rozwoju języka i komunikacji interpersonalnej. Psychol Rozw 2014;19(2):49-65.

40. Filimon F, Nelson JD, Hagler DJ, Sereno MI. Human cortical representations for reaching: mirror neurons for execution, observation, and imagery. Neuroimage 2007;37(4):1315-28.

41. Iacoboni M, Mazziotta JC. Mirror neuron system: basic findings and clinical applications. Ann Neurol 2007;62(3):213-8.

42. Rizzolatti G, Craighero L. The mirror-neuron system. Annu Rev Neurosci 2004;27(1):169-92

43. Keysers C, Gazzola V. Unifying social cognition. In: Pineda J, editor. Mirror neuron systems. The role of mirroring processes in social cognition. New York: Humana Press; 2009. p. 3-37.

44. Le Bel RM, Pineda JA, Sharma A. Motor-auditory-visual integration: the role of the human mirror neuron system in communication and communication disorders. J Commun Disord 2009;42(4):299-304.

45. Burke SN, Barnes CA. Neural plasticity in the ageing brain. Nat Rev Neurosci 2006;7(1):30-40.

46. Wołkowski P. Biologiczne aspekty teorii zdolności językowej Chomsky’ego. Diametros 2010;23:145-61.

47. Rizzolatti G. The mirror neuron system and its function in humans. Anat Embryol (Berl) 2005;210(5-6):419-21.

48. Kalat JW. Biologiczne podstawy psychologii. Warszawa: PWN; 2006

49. Wan CY, Demaine K, Zipse L, Norton A, Schlaug G. From music making to speaking: engaging the mirror neuron system in autism. Brain Res Bull 2010;82(3-4):161-8.

50. Głowacka K. Hipoteza rozbitego lustra a trudności rozwijania teorii umysłu u osób ze spektrum autyzmu - przegląd literatury i aktualny stan badań. Teraźniejszość-Człowiek-Edukacja 2019;22(86):41-56.

51. Chorab G. Neurolingwistycznie programowana edukacja. General Professional Educ 2016;2:3-9.

52. Mudrecka I. Proces resocjalizacji w perspektywie dorobku neuronauk. Polish J Soc Rehabil 2015;10:15-25.

53. Hickok G. Mit neuronów lustrzanych. Kraków: Copernicus Center Press; 2016. 